\section{Phenol red thread test vs Schirmer's test: a comparative study}

\begin{abstract}
Aim To measure the agreement between Schirmer's and phenol red thread tests in detecting dry eyes.

Patients and methods A total of 103 patients attending preoperative cataract assessment clinic who agreed to be involved in the study were recruited. Each patient had one eye examined by both tests in a random order by two different investigators who were unaware of the results of the other test. Dry eye symptoms were assessed using an intervieweradministered questionnaire. The data were collected after the study period and analysed using kappa statistics to assess the agreement between the two tests.

Results Schirmer's test was positive in 25 patients when a cutoff point of $5 \mathrm{~mm}$ was used and positive in 41 patients with a cutoff point of $10 \mathrm{~mm}$. Phenol red thread test was positive in four patients when a cutoff point of $10 \mathrm{~mm}$ was used and in 32 patients with a cutoff point of $20 \mathrm{~mm}$. Kappa ranged from 0.067 to 0.3 indicating very weak agreement between the two tests. In all, $27 \%$ of the patients had symptoms of dry eyes; however, the agreement between each test and the symptoms was very poor.

Conclusion There is very weak agreement between Schirmer's test and phenol red thread tests and between each test and symptoms of dry eyes.

Eye (2006) 20, 913-915. doi:10.1038/sj.eye.6702052; published online 5 August 2005
\end{abstract}

Keywords: Schirmer; phenol red; agreement; dry eyes

\section{Introduction}

Symptoms of dry eyes are relatively common in the general population particularly the
TA Saleh, B McDermott, AK Bates and P Ewings

elderly. ${ }^{1,2}$ Dry eye symptoms are common following LASIK and a reliable test to help predict the likelihood of dry eyes following refractive surgery would be valuable to the refractive surgeon. Several clinical and investigational tests have been used to assist the clinician in diagnosing and monitoring patients with dry eyes.

These include clinical history, tear film appearance on slit lamp examination, tear break up time, Fluorescein, Rose Bengal and Lissamine green staining, assessing tear osmolality, Schimer's test, and phenol red thread test.

Schimer's $\mathrm{s}^{3}$ test was introduced over a hundred years ago and is still commonly used in clinical practice. Hamano $e t a l^{4}$ introduced phenol red thread test in 1982. It has some advantages over Schirmer's test as it is more comfortable to the patient and the test is much quicker to perform.

In our study we assessed the agreement between the two tests and between each of the tests and dry eye symptoms.

\section{Methods}

Subjects were recruited from a cataract preoperative assessment clinic. Informed consents were obtained and the local ethical committee approved the study. One eye of each patient was randomly chosen to be examined by both tests. Eyes with previous ocular surgery were excluded. The order in which the two tests were undertaken was randomised by the toss of a coin. The second test was performed at least 5 min after the first one. Each test was undertaken by a different investigator who was unaware of the result of the other test.

A dry eye symptoms questionnaire was administered in a standardised fashion to each patient by one investigator.
Taunton and Somerset Hospital, Taunton, UK

Correspondence: TA Saleh, Eye Department, Royal Devon and Exeter Hospital (wonford),

Barrack Road,

Exeter, Devon EX2 5DW, UK

Tel: + 4407961426462 ;

Fax: + 4407092179986

E-mail: tareksaleh@

doctors.org.uk

Received: 18 April 2005

Accepted: 30 June 2005

Published online: 5 August 2005

The authors have no financial, commercial, or proprietary interests related to the products or manufacturers described in this article 


\section{Schirmer's test}

Schirmer tear test strips (Clement Clarke) were used according to the manufacturer's instructions. No topical anaesthetic was used. The rounded wick end of the test strip was folded at the indentation and then was inserted into the lower fornix of the eye $1 / 3$ of the distance from the lateral canthus of the lower eye lid.

After $5 \mathrm{~min}$, the strip was removed and the wet part was measured up to the folded line. A reading of less than $5 \mathrm{~mm}$ was judged to indicate dry eyes and less than $10 \mathrm{~mm}$ marginally dry eyes.

\section{Phenol red thread test}

Phenol red thread tear test (ZONE-QUICK, Showa Yakuhin Kako Co., Ltd) was used. The thread is yellow in colour (acidic) and when it comes in contact with tears it changes to a light red colour. No topical anaesthetic was used. Forceps were used to insert the $3 \mathrm{~mm}$ folded portion of the thread into the palpebral conjunctiva of the eye $1 / 3$ of the distance from the lateral canthus of the lower eye lid.

After $15 \mathrm{~s}$, the thread was removed and the entire wet (Red) portion was measured. A reading of less than $10 \mathrm{~mm}$ was judged to indicate dry eyes, less than $20 \mathrm{~mm}$ marginally dry eyes, and more than $20 \mathrm{~mm}$ normal tear volume.

\section{Dry eye symptoms questionnaire}

A validated ${ }^{1}$ questionnaire relating to six symptoms of dry eyes was administered to each patient in standardised fashion (Table 1). Patients were asked to report the frequency of each symptom as rarely, sometimes, often, or all the time.

The data were collected after the study period and analysed using kappa statistics ${ }^{5}$ (Kappa $=0$ is agreement no better than chance and Kappa $=1$ is total agreement) to assess the agreement between the two tests and between the tests and symptoms score.

\section{Results}

In total, 103 patients attending a preassessment clinic for cataract surgery were recruited to the study. There were

Table 1 Dry eye questionnaire

1 Do your eyes ever feel dry?

2 Do you ever feel a gritty or sandy sensation in your eye?

3 Do your eyes ever have a burning sensation?

4 Are your eyes ever red?

5 Do you notice much crusting on your lashes?

6 Do your eyes ever get stuck shut in the morning?
63 female and 40 male subjects, age ranged from 23 to 92 (mean 76) years. All patients were Caucasians.

Schirmer's test was positive in 25 patients when a cutoff point of $5 \mathrm{~mm}$ was used and was positive in 41 patients with a cutoff point of $10 \mathrm{~mm}$. Phenol red thread test was positive in four patients when a cutoff point of $10 \mathrm{~mm}$ was used and in 32 patients with a cutoff point of $20 \mathrm{~mm}$.

There was very weak agreement between the two tests using different cutoff points as measured by Kappa statistics. Kappa ranged from 0.067 using a cutoff point of $10 \mathrm{~mm}$ for both tests to 0.3 using a cutoff point of $5 \mathrm{~mm}$ for Schirmer and $20 \mathrm{~mm}$ for phenol red thread test (Table 2).

A total of 28 (27\%) of patients had dry eyes symptoms. The severity of symptoms ranged from 1 to 12 according to the dry eye questionnaire.

The tests had very poor agreement with symptoms of dry eyes (Table 3 ).

\section{Discussion}

The phenol red thread (PRT) test was developed to overcome the disadvantages of Schirmer's test including variable results, poor repeatability, and low sensitivity in detecting dry eyes. A test time of only $15 \mathrm{~s}$ is required in comparison to $5 \mathrm{~min}$ per eye needed for Schirmer test. It causes minimal discomfort and therefore is less likely to induce reflex tear production.

The PRT is theorised to measure the volume of the residual tear film in the inferior conjunctival sac of the eye. ${ }^{6}$

Table 2 Kappa agreement for different cutoff points for Schirmer test and phenol red thread test

\begin{tabular}{lll}
\hline & $\begin{array}{l}\text { Phenol red thread } \\
\text { test cutoff } \\
\text { point } 10 \mathrm{~mm}\end{array}$ & $\begin{array}{l}\text { Phenol red thread } \\
\text { test cutoff } \\
\text { point } 20 \mathrm{~mm}\end{array}$ \\
\hline $\begin{array}{l}\text { Schirmer test cutoff } \\
\text { point } 5 \mathrm{~mm}\end{array}$ & Kappa $=0.15$ & Kappa $=0.30$ \\
$\begin{array}{l}\text { Schirmer test cutoff } \\
\text { point } 10 \mathrm{~mm}\end{array}$ & Kappa $=0.067$ & Kappa $=0.22$ \\
\hline
\end{tabular}

Table 3 Kappa agreement between dry eyes symptoms and each test using different cutoff points

\begin{tabular}{ll}
\hline & Dry eyes symptoms \\
\hline Schirmer test cutoff point $5 \mathrm{~mm}$ & Kappa $=0.01$ \\
Schirmer test cutoff point $10 \mathrm{~mm}$ & Kappa $=0.12$ \\
Phenol red thread test cutoff point $10 \mathrm{~mm}$ & Kappa $=0.0$ \\
Phenol red thread test cutoff point $20 \mathrm{~mm}$ & Kappa $=-0.08$ \\
\hline
\end{tabular}


Tomlinson et al $^{7}$ concluded that PRT is unlikely to measure tear volume or residual tear in the lower conjunctiva. They thought that it more likely measures uptake of small amount of fluid residing in the eye and it may stimulate a low degree of reflex tearing. They suggested that PRT reflects some other aspect of tears that allow differentiation between dry eye patients and normal subjects through different absorption characteristics of the thread depending on the biophysics or composition of tears in these two groups.

On the other hand, Schirmer test is thought to measure reflex tear production and possibly residual volume of tears in the eye and it has a significant inability to measure basal secretion rate even with the use of local anaesthesia. ${ }^{7,8}$

No previous study has measured agreement between the two tests. Chiang et $a l^{9}$ compared the results of the two tests on 66 normal eyes and 14 dry eyes. The average wet length of the PRT test was $20.33 \pm 8.7 \mathrm{~mm}$ for normal eyes $v s 8.1 \pm 8 \mathrm{~mm}$ for dry eyes and this was statistically significant. The average wet length for the Schirmer was $10.0 \pm 7.9 \mathrm{~mm}$ for normal eyes vs $14.6 \pm 9.8 \mathrm{~mm}$ for dry eyes and this was not statistically significant.

In a study by Nichols et al $^{10}$ assessing relationship between symptoms of dry eyes and various tear film tests, no patients had an abnormal PRT and Schirmer test combination.

Our study showed only weak agreement between the two tests; this is possibly because each test measures different aspects of the tear film.

We have also shown that the agreement between the symptoms as measured by the validated questionnaire and either test were poor for all the cutoff values used.

This confirms the results of other studies ${ }^{1,11}$ that show weak correlation among various tear film tests and between tear film tests and symptoms of dry eyes. This may be due to the absence of symptoms that is specific to dry eyes and also to the different mechanisms by which each test differentiate between normal and dry eyes.

\section{Conclusion}

Neither of the tests showed sensitivity in detecting patients with dry eye symptoms, and the agreement between the two tests was weak. In our study population the results of either of the tests used alone were found to be of low diagnostic value.

\section{References}

1 McCarty CA, Bansal AK, Livingston PM, Stanislavsky YL, Taylor HR. The epidemiology of dry eye in Melbourne, Australia. Ophthalmology 1998; 105: 1114-1119.

2 Moss SE, Klein R, Klein BE. Prevalence of and risk factors for dry eye syndrome. Arch Ophthalmol 2000; 118(9): 1264-1268.

3 Schirmer O. Studien zur physiologie und pathologie derTränenabsonderung und Tränenabfuhr. Graefes Arch Ophthal 1903; 56: 197-291.

4 Hamano H, Hori M, Mitsunaga S, Kojima S, Maeshima J. Tear test (preliminary report). J Jpn CL Soc 1982; 24: 103-107 (in Japanese).

5 Altman DG. Practical Statistics for Medical Research. Chapman and Hall: London, 1991.

6 Sakamoto R, Bennett ES, Henry VA, Paragina S, Narumi T, Izumi $Y$ et al. The phenol red thread tear test: a crosscultural study. Invest Ophthalmol Vis Sci 1993; 34(13): 3510-3514.

7 Tomlinson A, Blades KJ, Pearce EI. What does the phenol red thread test actually measure? Optom Vis Sci 2001; 78(3): 142-146.

8 Clinch TE, Benedetto DA, Felberg NT, Laibson PR. Schirmer's test. A closer look. Arch Ophthalmol 1983; 101(9): 1383-1386.

9 Chiang B, Asbell PA, Franklin B. Phenol-red thread test and Schirmer test for tear production in normal and dry eye patients. Invest Ophthalmol Vis Sci 1988; 29(Suppl): 337.

10 Nichols KK, Nichols JJ, Lynn Mitchell G. The relation between tear film tests in patients with dry eye disease. Ophthal Physiol Opt 2003; 23(6): 553-560.

11 Schein OD, Tielsch JM, Munoz B, Bandeen-Roche K, West S. Relation between signs and symptoms of dry eye in the elderly. A population-based perspective. Ophthalmology 1997; 104(9): 1395-1401. 